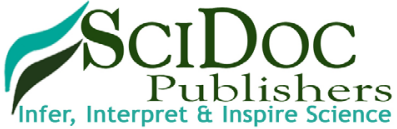

International Journal of Food Science, Nutrition and Dietetics (IJFS)

ISSN:2326-3350

\title{
Towards a more Holistic Vision of Human Nutrition to Prevent from Diet-Related Chronic Diseases: The Reductionist Drift
}

Editorial

Fardet A

INRA, UMR 1019, UNH, CRNH Auvergne, F-63000 CLERMONT-FERRAND \& Clermont Université, Université d'Auvergne, Unité de Nutrition Humaine, BP 10448, F-63000 CLERMONT-FERRAND, France.

\section{Diet and Reductionist Drift}

When asked the general public what the attributes, for example, the health potential of dairy products, citrus fruits, meat or grain products, it mostly responds, respectively, calcium, vitamin C, protein and fiber. These responses if they are partially true, are also partially false. In fact, they reduce the health food potential to a single nutrient. But foods are complex matrices consisting of hundreds of nutrients. And it is the synergistic action of these nutrients as well as the structure of the food matrix in which they are included which determine their protective effects. Thus, the milk is a highly complex food containing a wide variety of proteins and lipids, sugars, minerals, trace elements and vitamins. Therefore, milk health potential can not be reduced to a single calcium. The usual response of the general public clearly reflect how the paradigm of the "reductionist" thought invaded our vision. But probably research in food science and popularized communication of results are primarily responsible!

By definition, the reductionist approach fractionated reality, first considered as too complex to be studied as such, into isolated elements to better studied them. In other words, it is considered that the whole is equal to the sum of the parts, that is to say that $1+1=2$. In research associated with the food industry, this has led to fractionate foods - considering them as an only sum of nutrients and then to isolate the ingredients for then recombine them with often adding salts, fats and sugars (particularly in order to give them the taste they had lost!) [1]. Fractionation of wheat grain into white refined flour, bran (the envelope of the wheat) and germ, perfectly illustrates the consequences of this technological reductionism that led him to bring to market high-energy grain products and lacking protective fiber and micro nutrients, such as white bread or ready-to-eat breakfast cereal for children (coming from a drastic technological transformation and fortified with sugar, fat, salt, and/or sometimes minerals and vitamins). This extreme food cracking is also found with the milk, eggs and meat, leading to ever more highly processed foods.

Then we try to correct the nutritional imbalance, caused by these ultra-processed and refined foods eaten in large quantities, with food supplements or functional foods (e.g., margarine with added phytosterols [2] or milk enriched with omega-3 are expected to participate to better cardiovascular health) that represent the final stage of nutritional reductionism. However, scientific evidence clearly shows that these supplements do not improve health in the long term, and do not allow to reduce the risk of chronic diseases; on the contrary, sometimes the risk is increased [3, 4]. Reductionism has led to consider preventive nutrition according to a pharmacological perspective and nutrients as drugs that one could isolate and administer at high doses [5].

In addition, at the same time that our diet evolved, our physical activity decreased, and nutrition education in school curriculum (especially for protection against marketing pressure) remained far too inadequate ...

The reductionist approach involved in the increasing development of chronic diseases: a disastrous statistical report!

When the ultra-processed foods are the basis of our diet, then we create a favorable ground for the development of chronic diseases. For example, the science clearly shows that massive support to regimes based on ultra-processed foods (e.g., Western omnivorous diet high in energy, ultra-processed and refined foods), as can be observed in some cities, tends to increase the risk of obesity, type 2 diabetes (non-insulin dependent diabetes), cardiovascular diseases and cancer (among the 4 major public health issues) but also mortality ...

*Corresponding Author:

Anthony Fardet,

INRA, UMR 1019, UNH, CRNH Auvergne, F-63000 CLERMONT-FERRAND \& Clermont Université, Université d'Auvergne, Unité de Nutrition Humaine, BP 10448, F-63000 CLERMONT-FERRAND, France.

E-mail: anthony.fardet@clermont.inra.fr

Received: January 29, 2016

Published: February 04, 2016

Citation: Fardet A (2016) Towards a more Holistic Vision of Human Nutrition to Prevent from Diet-Related Chronic diseases: the reductionist drift. Int J Food Sci Nutr Diet. 5(1e), 1- 2. doi: http://dx.doi.org/10.19070/2326-3350-160005e

Copyright: Fardet $\mathbf{A}^{\circ}$ 2016. This is an open-access article distributed under the terms of the Creative Commons Attribution License, which permits unrestricted use, distribution and reproduction in any medium, provided the original author and source are credited. 
In France, according to data from the French Social Security, there were, in 2010, 539, 083 deaths, of which about $36 \%$ could be attributed directly or indirectly to poor diet (24\% for cardiovascular disease, $10 \%$ for cancer and $2 \%$ for diabetes). In 2014, it reached the figure of $50 \%$ of the adult population overweight (Body Mass Index or BMI>25). And, according to the High Authority of Health in France, in 2012 more than 15 million French suffer from a chronic disease, these representing nearly $2 / 3$ of health spending.

Because of these increased prevalence of chronic diseases, the average years of life spent in good health tend to decrease (62-64 years in 2009 for French); while the theoretical life expectancy continues to increase by about three months every year (79-85 years in 2009 for French). So we are living longer and longer, but longer in poor health.

\section{Towards a more holistic approach to food}

The reductionist approach tends to generalize from the particular, which is risky, even wrong. The reality is indeed first complex, and therefore society problems are: scientists should therefore first go from society and use science to address complex society issues in a comprehensive or holistic perspective (from the ancient Greek bolos meaning "all, the whole").

Basically, holism considers first of all that "the whole is greater than the sum of its parts", so that $1+1>2$ ! This is especially true for nutrition, or more generally food, which are essentially holistic science involving both philosophical, religious, socio-cultural, economic, environmental, behavioral, physiological, technological and/or metabolic dimensions.
So rather than trying to correct an unbalanced diet with food supplements according to a curative and reductionist logic, should be promoted from the start a diet based on complex and minimally processed foods, diverse and balanced - to avoid falling into the funnel of chronic diseases.

Being concerned over the complex reality of society, nutrition and food researchers could further contribute to improving public health. The holistic approach is now essential in human nutrition among dieticians, nutritionists, physicians than among food researchers. It is only at this price that effective nutritional recommendations maybe proposed to the greatest number [6].

\section{References}

[1]. Fardet A, Rock E (2014) Toward a new philosophy of preventive nutrition: from a reductionist to a holistic paradigm to improve nutritional recommendations. Adv Nutr 5: 430-446.

[2]. Fardet A, Morise A, Kalonji E, Margaritis I, Mariotti F (2015) Influence of phytosterol and phytostanol food supplementation on plasma liposoluble vitamins and provitamin A carotenoid levels in humans: An updated review of the evidence. Crit Rev Food Sci Nutr.

[3]. Fardet A (2015) Complex foods versus functional foods, nutraceuticals and dietary supplements: differential health impact (Part 2). Agro Food Industry Hi-tech 26(3): 20-22.

[4]. Fardet A (2015) Complex foods versus functional foods, nutraceuticals and dietary supplements: differential health impact (Part 1). Agro Food Industry Hi-tech 26(2): 20-24.

[5]. Fardet A, Rock E (2014) The search for a new paradigm to study micronutrient and phytochemical bioavailability: from reductionism to holism. Med Hypotheses 82(2): 181-186.

[6]. Fardet A, Rock E (2015) From a reductionist to a holistic approach in preventive nutrition to define new and more ethical paradigms. Healthcare 3(4): 1054-1063. 